\title{
New approaches in the development of a vaccine for mucosal candidiasis: progress and challenges
}

\section{Anna Vecchiarelli*, Eva Pericolini, Elena Gabrielli and Donatella Pietrella}

Microbiology Section, Department of Experimental Medicine and Biochemical Sciences, University of Perugia, Perugia, Italy

\section{Edited by:}

Joshua D. Nosanchuk, Albert Einstein

College of Medicine, USA

Reviewed by:

Leonardo Nimrichter, Federal

University of Rio de Janeiro, Brazil

Joseph M. Bliss, Women and Infants

Hospital of Rhode Island, USA

*Correspondence:

Anna Vecchiarelli, Microbiology

Section, Department of Experimental

Medicine and Biochemical Sciences,

University of Perugia, Via del

Giochetto, 06126 Perugia, Italy.

e-mail:vecchiar@unipg.it

\begin{abstract}
The commensal fungus Candida albicans causes mucosal candidiasis in the rapidly expanding number of immunocompromised patients. Mucosal candidiasis includes oropharyngeal, esophageal, gastrointestinal, and vaginal infections. Vulvovaginal candidiasis (VVC) and antimycotic-refractory recurrent VVC is a frequent problem in healthy childbearing women. Both these mucosal infections can affect the quality of life and finding new therapeutical and preventive approaches is a challenge. A vaccine against candidal infections would be a new important tool to prevent and/or cure mucosal candidiasis and would be of benefit to many patients. Several Candida antigens have been proposed as vaccine candidates including cell wall components and virulence factors. Here we discuss the recent progress and problems associated with vaccination against mucosal candidiasis.
\end{abstract}

Keywords: mucosal candidiasis, $C$. albicans, vaccine, fungal infections, candidiasis

\section{INTRODUCTION}

Candida albicans is a dimorphic fungus that colonizes different areas of the body from the gastrointestinal tract to oral and vaginal mucosa. It is usually a commensal microorganism but in immunocompromised or otherwise debilitated hosts it can cause disseminated and mucosal candidiasis. Systemic candidiasis is the fourth most common hospital-acquired infection in the USA (Pfaller et al., 1998a,b). The associated mortality depends on host conditions, and ranges between 30 and 50\% (Pfaller et al., 1998b; Kibbler et al., 2003). Invasive fungal infections are common and severe in patients with hematologic malignancies, leading to particularly high mortality. Somewhat different from systemic infections, mucosal infections are common not only in immunocompromised patients but also in apparently normal subjects (Kirkpatrick, 2001). Their most common sites are the oral cavity, and the gastrointestinal and vaginal tracts. Oral thrush is one of the most frequent clinical forms of mucocutaneous candidiasis. It occurs at all ages with aggressive symptoms especially in infants and elderly people (Lopez-Martinez, 2010).

Vulvovaginal candidiasis (VVC) is a common distressing infection that affects up to $75 \%$ of childbearing women worldwide at least once in their life. Up to $7 \%$ of these women suffer from frustrating recurrent infection (RVVC) defined as at least three or four episodes of acute VVC in 1 year (Fidel, 2007; Sobel, 2007). Two forms of RVVC have been described: idiopathic (Id) primary RVVC with unknown predisposing factors, and secondary RVVC which occurs under predisposing conditions such as antibiotic treatment, oral contraceptive use, or diabetes mellitus (Fidel, 2004). These infections affect the quality of life, and require frequent antimycotic treatment enhancing the risk of acquiring drug resistance (Cassone, 2007).

Overall, the growing impact of fungal diseases has resulted in renewed interest in new approaches for improving their control. Among these new approaches, the generation of fungal vaccines is recognized as a priority. A mucosal vaccine would improve the quality of life of a long list of target populations of women suffering from RVVC. The aim of this review is to discuss the recent progress and problems associated with the development of a protective mucosal vaccine against candidiasis.

\section{INNATE IMMUNE RESPONSE AT MUCOSAL SURFACES}

The immunopathology associated with mucosal candidiasis is still not completely understood. The presence of C. albicans as a commensal on the mucosal surface does not go unnoticed or tolerated by the host - humoral and cellular factors of the innate and acquired immune response play an important role in limiting the growth of the fungus and neutralizing the activity of the virulence factors (Cassone et al., 2007). Indeed the transition from asymptomatic colonization to symptomatic infection occurs when the local defenses are impaired and when the fungus becomes more aggressive causing epithelial damage and inflammation through the production of virulence factors. In addition, alteration of the normal microbiota plays an important role.

The mucosal microbiota is acquired by colonization when passing through the birth canal, and soon after birth. The commensals establish their residence in mucosal niches where they replicate and play a crucial role in the development of the immune system. The immune response to the microbiota at the mucosal surface helps to maintain barriers to potentially harmful microorganisms (Pirofski and Casadevall, 2012). C. albicans as a commensal microorganism is part of normal microbiome in specific niches such as the oral cavity, vagina, and gut in at least $50 \%$ of healthy individuals. However it can cause pathology following alterations of the local environment and/or impairment of the immune response. To persist within the human host and cause disease at the mucosal surfaces, C. albicans has acquired several distinct factors enabling these microorganisms to adhere to and invade host cells. 
Epithelial cells (ECs) lining the mucosa play an essential role in the defense against C. albicans. Indeed at the mucosal surface ECs sense the presence of Candida and elaborate a number of mechanisms to tolerate its presence and limit adherence, penetration, and damage. It is clear that ECs recognize the fungus and are capable of distinguishing its different forms of growth (Moyes et al., 2010), however the relative role of pattern recognition receptors (PRRs) in ECs is still largely unclear, despite the intensive research in PRRmediated interaction of C. albicans with myeloid cells (Netea et al., 2006, 2008). The recognition of C. albicans by these cells has largely been elucidated and the major PRRs and their putative ligands derived from $C$. albicans have been extensively studied (Roeder et al., 2004a,b; Netea et al., 2006). It is known that ECs express PRRs: toll-like receptors (TLRs), dectin-1, and galectins (Backhed and Hornef, 2003; Hornef and Bogdan, 2005; Weindl et al., 2007). TLR2 and TLR5 are expressed at particularly high levels and these receptors have been associated with biological functions of ECs such as growth, survival, and repair (Rhee et al., 2005; Shaykhiev et al., 2008).

\section{CANDIDA RECOGNITION AT THE MUCOSAL SURFACE}

Compelling evidence shows that $C$. albicans recognition by TLR4 on monocytes/macrophages results in release of proinflammatory cytokines such as IL-1 and TNF- $\alpha$ (Netea et al., 2006) and also the stimulation via TLR2 and Fc $\gamma$ RII leads to TNF- $\alpha$ production (Netea et al., 2008). TLR4, which is highly expressed on myeloid cells and plays a critical role in driving immune response against C. albicans (Netea et al., 2006), is poorly expressed in ECs at the oral mucosal surface (Backhed and Hornef, 2003), and it seems that TLR4 does not have a role in cytokine induction in response to Candida (Li and Dongari-Bagtzoglou, 2009) and to other TLR4 ligands such as LPS (Naglik and Moyes, 2011).

At present, which fungal cell wall structures are recognized in oral ECs is also unknown, however a recent study has established that human oral ECs have a direct antifungal activity demonstrating the important role of these cells in mucosal protection (Weindl et al., 2007). Indeed, the oral epithelium is able to induce various defense effector molecules (Diamond et al., 2008) and to orchestrate an immune response to activate immune cells in the submucosal layers to clear the invading pathogens (Cutler and Jotwani, 2006). It has also been reported that after fungi recognition, infected ECs are activated and they produce proinflammatory cytokines and chemokines including IL-8 which induces neutrophil recruitment (Weindl et al., 2007; Moyes and Naglik, 2011) into the mucosa surface. This could be considered a mechanism of immune surveillance (Moyes and Naglik, 2011). However, despite the beneficial role of these cells in protection against systemic candidiasis, PMNs seem to exert no protective role in vaginal candidiasis. Neutrophils are abundantly recovered during vaginal candidiasis, but their presence was not associated to reduction of fungal burden (Fidel et al., 1999). On the contrary, it has been hypothesized that ECs have high sensitivity to Candida and secrete S100 alarmin resulting in a vigorous PMN migration which results in an inflammatory response and symptoms of infection (Yano et al., 2010). In agreement with this, a live challenge model in humans recently revealed that symptomatic vaginitis is caused by an aggressive innate response (neutrophil infiltrates and elevated fungal burden in the vaginal lumen); the protection has been associated to a non-inflammatory innate response (Fidel, 2007). Therefore the capacity of ECs to recruit and activate neutrophils might be a double-edged sword, with both favorable and unfavorable consequences depending on the specific niche.

There is no doubt, therefore, that many aspects of EC interaction with C. albicans, including the recognition of specific antigens and regulation of the complicated network of regulatory activities that characterize commensalism and infection in different niches, remain to be studied.

\section{T CELL RESPONSE IN MUCOSAL CANDIDIASIS}

The role of $\mathrm{T}$ cells in mucosal candidiasis has only been partially elucidated, and the attempt to integrate the defense response to systemic and mucosal candidiasis remains inconclusive (Ashman et al., 2011). There is a wealth of studies reporting that Th1-type immunity is dependent on the presence of IL-12 in the milieu (Trinchieri, 2003) and compelling evidence indicates that the Th1 response is protective against mucosal candidiasis. The beneficial role of the Th1 response in oral candidiasis in particular has been underlined (Schaller et al., 2004). In agreement with these findings is the marked susceptibility of HIV-infected subjects to oral candidiasis when $\mathrm{CD}^{+} \mathrm{T}$ cells are depleted, suggesting a role for both Th1 and Th17 cell functional CD4 subsets. In addition, depletion of IL-12 resulted in acute susceptibility to oral infection in a mouse experimental model (Farah et al., 2002; Fidel, 2006; Zakikhany et al., 2007). In a report by Conti et al. (2009) susceptibility to oropharyngeal candidiasis (OPC) in mice with impaired Th1 and/or Th17 responses was compared. In this study fungal infections of the tongue were less severe in mice lacking IL-12p35 than in mice lacking IL-23p19, suggesting that Th17 responses play a central role in control of infection. However, the fungal burden in both IL-12p35- and IL-23p19-deficient mice was substantially higher than in controls, evidencing that the absence of either Th1 or Th17 cells impaired the ability of the mice to limit fungal growth (Pirofski and Casadevall, 2009). As well as driving innate immunity and neutrophil responses, Th17 cells have also been shown to drive antibody responses at mucosal surfaces, in particular secretory IgA (Moyes and Naglik, 2011).

\section{HUMORAL RESPONSE IN MUCOSAL CANDIDIASIS}

For many years antibodies have been considered irrelevant in the host defense against invasive candidiasis, but evidence for this mode of protection has been mounting over the last two decades. Indeed a number of antibodies or their engineered derivatives directed against $C$. albicans cell wall compounds have been shown to confer protection (Cutler et al., 2007, 2011; Cassone and Rappuoli, 2010; Xin and Cutler, 2011). The discovery of numerous antigens on the fungal cell wall that elicit protective antibody responses raises the possibility of vaccines designed with multiple antigens, and/or passive therapies that combine antibodies with different specificities (Casadevall et al., 2004; Casadevall and Pirofski, 2007).

Protective antibodies have been reported for C. albicans cell wall polysaccharides, proteins, and peptides (De Bernardis et al., 1997; 
Matthews et al., 2003; Cutler, 2005; Yang et al., 2005; Xin et al., 2008). As a prevention strategy, protection against disease may be actively or passively acquired by vaccination and the administration of preformed monoclonal antibodies (Xin and Cutler, 2011).

In early studies protection against vaginal candidiasis was associated with the presence of protective antibodies against Candida constituents in the vaginal fluids and increased number of activated lymphocytes in the vaginal mucosa (De Bernardis et al., 1997; de Bernardis et al., 2000). More recently the same group demonstrated that vaginal B cells play an important role in protection against vaginal candidiasis suggesting that the contribution of T cells is predominantly that of helping $\mathrm{B}$ cells in protective antibody production (De Bernardis et al., 2010). Recently, treatment with synthetic peptides whose sequences are identical to fragments from the constant region of different classes of antibodies has been shown to provide protection against experimental vaginal candidiasis (Polonelli et al., 2012), and a protective effect in vaginal candidiasis was also noticed after passive administration of anti- $\beta$ glucan mAbs (Torosantucci et al., 2009). Unfortunately, the role of Abs has rarely been investigated in other mucosal infections such as oral candidiasis.

\section{ANTI-CANDIDA VACCINES AND PROTECTION MECHANISMS}

Recent papers support the idea that it may be possible to develop an antifungal vaccine that grants protection against multiple fungal pathogens (Cassone and Rappuoli, 2010; Stuehler et al., 2011; Wuthrich et al., 2011). Some studies have focused on cell-mediated immunity as the mechanism of protection (Spellberg et al., 2008), which is in accordance with the literature (Xin et al., 2008), whereas others (Cutler et al., 2007; Karwa and Wargo, 2009; Torosantucci et al., 2009) have determined that antibodies specific to certain Candida antigens are protective. Because of the variegate nature of Candida virulence and participation of different host responses in protection, it may well be possible that both humoral and cellular responses play a role in vaccination, providing the necessary collaboration to grant protection.

Several papers suggest that the induction of strong cellular immunity plays a paramount role in protection against candidiasis. One approach for stimulating cellular immunity was priming ex vivo dendritic cells (DCs) with fungal cells and re-administering the loaded DCs to the host (Roy and Klein, 2012). Less recent papers showed that DCs transfected with fungal RNA adoptively transferred into otherwise susceptible recipients, did in fact confer protection against $C$. albicans by inducing a protective Th1 response (Bozza et al., 2004; Perruccio et al., 2004). Recently a novel antigenic peptide, derived from a cell wall-associated adhesion and recognized by a major population of all Candida-specific Th cells isolated from infected mice, was isolated and sequenced from infected DCs. This peptide contributes to fungal pathogenicity and it is conserved in many clinically important Candida species such as $C$. dubliniensis and C. glabrata. Of note is the fact that human Th cells also responded to stimulation with the peptide. Furthermore when this peptide is used in combination with an adjuvant inducing IL-17A secretion, it acts as an efficient vaccine by protecting mice from fatal candidiasis (Bar et al., 2012).
The fungal-specific antibody-mediated protection may occur not only through classical immunological responses such as phagocytosis and killing and complement activation, but also through direct antibody actions on fungal cells, and even though antibody protection is considered specific many fungal antigens may be used for vaccination and to obtain therapeutic immunoglobulins (Casadevall and Pirofski, 2012). The novel fully synthetic $\beta$-(Man)3-Fba glycopeptide vaccine that represents two epitopes of $C$. albicans cell surface has been shown to be protective in an experimental model of systemic candidiasis (Xin et al., 2008). The protection was afforded with a strong antibody response that was achieved by using a DC/Complete Freund Adjuvant (CFA) combination (Xin et al., 2008). Indeed the antigenpulsed DC proved to be a powerful means to induce a potent immune response that was not achieved by using small carbohydrate and peptide antigens of $C$. albicans. More recently, by coupling $\beta$-(Man)3-Fba glycopeptide to tetanus toxoid to render this vaccine entirely compatible with human use, a high degree of antibody-mediated protection was observed (Xin et al., 2012). These vaccine formulations also proved protective in mucosal models of infection (Xin et al., 2012). Another important effort to induce protection against $C$. albicans was made by $\mathrm{Li}$ et al. (2011) who showed that treatment with recombinant enolase, an important glycolytic enzyme located on the cell wall of C. albicans, conferred a protective effect against systemic challenge evaluated by fungal burdens in target organs, titers of specific antibodies to enolase, and levels of Th1/2 cytokines in serum.

\section{VACCINE CANDIDATES FOR MUCOSAL CANDIDIASIS}

Strategies to elaborate a vaccine for mucosal candidiasis should take into account what type of immune response is protective under natural conditions, but should not necessarily be limited to mimicking the natural history of mucosal infection and protection. Hence, several studies have focused on different strategies to induce protection against vaginal candidiasis. In particular, it has been reported that vaccination with the recombinant $\mathrm{N}$ terminus of the candidal adhesin rAls $3 \mathrm{p}-\mathrm{N}$ protects mice against disseminated and oropharyngeal and vaginal candidiasis by a cellmediated immune response (Th1/Th17). Antibodies have also been generated but their titers did not correlate with protection. The rAls $3 \mathrm{p}-\mathrm{N}$ vaccine is a promising new vaccine candidate for further exploration to prevent systemic and mucosal candidal infections (Spellberg et al., 2006). It has recently completed a Phase 1 clinical trial and proved to be safe and immunogenic. In particular, this research group reported that vaginal and systemic protective responses could be achieved by vaccination with rAls3-N which stimulates Th1/Th17 lymphocytes to produce high levels of IFN- $\gamma$ and IL-17A, as well as the chemokines $\mathrm{KC}$ and MIP-1. These cytokines enhance the capacity of phagocytes to kill the pathogen. This vaccine protects immunocompetent mice from both vaginal candidiasis and lethal disseminated candidiasis and it also significantly reduces oral fungal burden in the corticosteroidtreated mouse model of OPC. Human trials with the rAls3-N vaccine are in final preparation (Liu and Filler, 2011). An additional approach to achieve protection against mucosal infection was immunization with $C$. albicans dsDNA which induces host resistance in newborn mice against gastrointestinal $C$. albicans 
infection. The protective properties of dsDNA are related to an increased number of CD $4^{+} \mathrm{T}$ cells secreting IFN- $\gamma$ (Remichkova et al., 2009).

One attempt to develop a mucosal vaccination was by using an aspartyl proteinase (Sap2), a very well known enzyme belonging to a family of virulence factors of C. albicans (Naglik et al., 2003). Previous clinical and experimental work strongly suggested that Sap2 and possibly other Saps were involved in vaginal infection (Cassone et al., 1987; De Bernardis et al., 1990). Mice immunized with Sap2 showed significantly reduced fungal burdens both orally and vaginally, and rats receiving intravaginal administration of antiSap2 antibodies were protected by an intravaginal challenge by C. albicans. These studies demonstrated that Sap2 is an immunogenic antigen capable of inducing protective responses against $C$. albicans colonization and infection, and tentatively supports its targeting as a potential vaccine candidate (Rahman et al., 2007). The role of Sap2 in inducing protection against mucosal candidiasis has more recently been underscored by Sandini et al. (2011). These authors generated a recombinant truncated Sap2 protein (rSap2t) and reported that intravaginal immunization with this antigen and cholera toxin as an adjuvant protected from the challenge of a highly vaginopathic strain of C. albicans. Protection was possibly due to the elicitation of specific antibodies IgM and IgG anti-rSap2t. More recently rSap2t was incorporated into influenza virosomes, an adjuvant/carrier formulation already used in other human vaccines, which avoids the necessity for a toxin adjuvant. This formulation generated a potent serum antibody response in the mouse and rat following intramuscular immunization. In a rat model of candidal vaginitis the intravaginal or intramuscular administration of rSap2 $t$ induced production of anti-Sap2 IgG and IgA in the vaginal fluid, which conferred a consistent degree of protection against vaginal C. albicans infection (De Bernardis et al., 2012).

In another study, murine mAb (KT4, IgG1) was used, neutralizing in vitro the anti-Candida activity as an Id vaccine to elicit Abs. An effective protection that correlated with a significant decrease in vaginal Candida CFU was obtained in Id-vaccinated animals compared with controls. The protection was associated with rising vaginal titers of anti-idiotypic Abs (IdAb), prevalently of the IgA isotype, that were able to passively transfer the protective state to non-immunized animals (Polonelli et al., 1994). Since the receptor of the killer toxin recognized by the mAbKT4 is a beta-glucan molecule, it is possible that the protection conferred by the Id vaccine somewhat parallels the protection conferred by the $\beta$-glucan-conjugate vaccine (see below).

In a further work, immunization was performed with C. albicans heat shock protein $90 \mathrm{kDa}$ (hsp90-CA). Intradermal priming with recombinant hsp90-CA protein, followed by an intranasal or intradermal booster with recombinant hsp90-CA protein, induced significant increases of specific IgG and IgA antibodies in both serum and vaginal fluid. The specific IgG isotype increased after vaginal Candida infection, suggesting that Candida has the ability to induce a local hsp90-specific antibody (IgG) response during VVC (Raska et al., 2008).

A vaccine composed of $\beta$-glucan has been considered a candidate against Candida and other fungi. A non-fungal source of $\beta$-glucan, laminarin, has been used in these studies. Because polysaccharides are poor immunogens, laminarin was conjugated with the diphtheria toxoid CRM197. This novel glyco-conjugate vaccine administered with human-compatible adjuvant resulted immunogenic and protective as a prophylactic against experimental systemic and mucosal infections by C. albicans (Torosantucci et al., 2005). The protection has been ascribed to the production of antibodies to $\beta$-(1,3)-glucan (Bromuro et al., 2010). The protective capacity of this $\beta$-glucan-conjugate vaccine formulated with the human-compatible MF59 adjuvant was assessed in a murine model of vaginal candidiasis exploiting an in vivo imaging technique to monitor the infection. The vaccine conferred significant protection, which was associated to anti- $\beta$-glucan IgG antibodies in the serum and in the vagina. The efficacy of the antibodies was demonstrated by the passive transfer of the immune vaginal fluid or anti- $\beta$-glucan monoclonal antibodies to naïve mice before infection (Pietrella et al., 2010). The main vaccine candidates are reported in Table 1.

\section{CONCLUSION}

Despite several promising approaches, the achievement of a vaccine against mucosal infections in humans still faces a number of problems and challenges. The major challenge remains the difficulties in translating results from rodents to humans, as rodent models can represent at best only part of the variegate patterns of vaginal Candida infections in women (Sobel, 2007). In fact most of the data indicating that protection against vaginal infection has been obtained in the rat model, and is not considered by some to be fully representative of the human infection (Fidel and Cutler, 2011). In addition, very few vaccination studies have addressed oral and other types of mucosal candidiasis. Another issue is that vaccine-induced protection must occur in specific niches where C. albicans is tolerated as a commensal organism, and it cannot be excluded that affecting fungus colonization by a vaccine could induce some harm in the host by affecting the mucosal microbiome. Other issues concern the search for new vaccine immunogens and adjuvants by existing advanced technologies. It should be taken into account that the most studied vaccines, particularly those in clinical trials (the virosomal Sap2 and the Als3 peptide) have been generated by classical "empiric" approaches, including clinical impressions. Now, a large variety of covalently attached proteins has been found in fungal walls and these proteins can rapidly change their expression in response to different environmental conditions. The knowledge of the specific proteome of the fungus in the host is fundamental for the identification of new vaccine candidates (Klis et al., 2011). Not only proteomics but also complementary post-genomic tools such as transcriptomics and metabolomics in a systems biology context will be useful tools to study pathogen-host interaction, to identify the protective response during infection and the immune response after vaccination. In a recent study, through an integrated analysis of genome-wide transcriptome, Lindqvist et al. determined which signature pathways, processes, and networks are shared by or are exclusive to two classes of experimental vaginal adjuvants, the TLR-9 agonist CpG-ODN and alpha-galactosylceramide in the mouse vagina. These molecular signatures could be used to develop potent mucosal adjuvants that can be used in the female genital tract of a mammal (Lindqvist et al., 2011). 
Table 1 | Vaccine candidates for protection against candidiasis.

\begin{tabular}{|c|c|c|c|}
\hline Components & Reference & Protective immunity & Protection \\
\hline \multirow[t]{2}{*}{ Mannoproteins } & De Bernardis et al. (2010) & B cells & Vaginal \\
\hline & Pietrella et al. (2002) & Th1 & Systemic \\
\hline$\beta$-1,2-mannotriose-Fba & Xin et al. (2012) & Abs & Systemic \\
\hline C. albicans surface protein, Als $3 p$ & Spellberg et al. (2008) & Th1-Th17 & Systemic \\
\hline (Agglutinin-Like Sequence 3) rAls3-N & Baquir et al. (2010), Liu and Filler (2011) & Abs & $\begin{array}{l}\text { Vaginal, systemic, } \\
\text { and oral }\end{array}$ \\
\hline Phosphoglycerate kinase & Calcedo et al. (2012) & Abs & Oral \\
\hline Secreted aspartic proteases 2 & $\begin{array}{l}\text { De Bernardis et al. (2012), Cassone and } \\
\text { Casadevall (2012) }\end{array}$ & Abs & Mucosal and vaginal \\
\hline Liposome-mannan (L-mann) & Han et al. (2000) & Abs to $\beta$-1,2-mannotriose & Systemic and vagina \\
\hline Daucosterol & Lim et al. (2007) & Th1 & Systemic \\
\hline Enolase & Li et al. (2011) & Abs Th1 & Systemic \\
\hline $\begin{array}{l}\text { Glycopeptide or a peptide synthetic } \\
\text { vaccine, (Candida albicans cell wall-derived) }\end{array}$ & Xin et al. (2012) & Abs & Systemic \\
\hline $\begin{array}{l}\text { Fba, (peptide derived from fructose } \\
\text { bisphosphate aldolase which has cytosolic } \\
\text { and cell wall distributions in the fungus) }\end{array}$ & Cutler et al. (2011) & Abs & Systemic \\
\hline C. albicans dsDNA & Remichkova et al. (2009) & T cells (Th1) & Gastrointestinal \\
\hline
\end{tabular}

NT, not tested.

Knowledge of the host mechanisms involved in candidiasis protection, and understanding of the fungal virulence factors, will allow the development of a novel topical mucosal vaccine.

\section{REFERENCES}

Ashman, R. B., Vijayan, D., and Wells, C. A. (2011). IL-12 and related cytokines: function and regulatory implications in Candida albicans infection. Clin. Dev. Immunol. 2011, 686597.

Backhed, F., and Hornef, M. (2003). Toll-like receptor 4-mediated signaling by epithelial surfaces: necessity or threat? Microbes Infect. 5, 951-959.

Baquir, B., Lin, L., Ibrahim, A. S., Fu, Y., Avanesian, V., Tu, A., Edwards, J. Jr., and Spellberg, B. (2010). Immunological reactivity of blood from healthy humans to the rAls3p$\mathrm{N}$ vaccine protein. J. Infect. Dis. 201, 473-477.

Bar, E., Gladiator, A., Bastidas, S., Roschitzki, B., Acha-Orbea, H., Oxenius, A., and LeibundgutLandmann, S. (2012). A novel Th cell epitope of Candida albicans mediates protection from fungal infection. J. Immunol. 188, 5636-5643.

Bozza, S., Montagnoli, C., Gaziano, R., Rossi, G., Nkwanyuo, G., Bellocchio, S., and Romani, L. (2004). Dendritic cell-based vaccination against opportunistic fungi. Vaccine 22, 857-864.

Bromuro, C., Romano, M., Chiani, P., Berti, F., Tontini, M., Proietti, D., Mori, E., Torosantucci, A., Costantino, P., Rappuoli, R., and Cassone, A. (2010). Beta-glucanCRM197 conjugates as candidates antifungal vaccines. Vaccine 28, 2615-2623.

Calcedo, R., Ramirez-Garcia, A., Abad, A., Rementeria, A., Ponton, J., and Hernando, F. L. (2012). Phosphoglycerate kinase and fructose bisphosphate aldolase of Candida albicans as new antigens recognized by human salivary

\section{ACKNOWLEDGMENTS}

This paper was supported by a grant, No. 2010.011.0398, from the Fondazione Cassa di Risparmio di Perugia. We thank Catherine MacPherson for editorial assistance.

IgA. Rev. Iberoam. Micol. 29, 172-174.

Casadevall, A., Dadachova, E., and Pirofski, L. A. (2004). Passive antibody therapy for infectious diseases. Nat. Rev. Microbiol. 2, 695-703.

Casadevall, A., and Pirofski, L. A. (2007). Antibody-mediated protection through cross-reactivity introduces a fungal heresy into immunological dogma. Infect. Immun. 75 , 5074-5078.

Casadevall,A., and Pirofski, L. A. (2012) Immunoglobulins in defense, pathogenesis, and therapy of fungal diseases. Cell Host Microbe 11, 447-456.

Cassone, A. (2007). "Fungal vaccines and vaccination: problems and perspective," in Immunology of Fungal Infections, Chap. 21, eds G. D. Brown and M. G. Netea (Dordrecht: Springer), 465-485.
Cassone, A., Bromuro, C., Chiani, P., and Torosantucci, A. (2010). Hyrl protein and beta-glucan conjugates as anti-Candida vaccines. J. Infect. Dis. 202, 1930

Cassone, A., and Casadevall, A. (2012). Recent progress in vaccines against fungal diseases. Curr. Opin. Microbiol. PMID: 22564747. [Epub ahead of print].

Cassone, A., De Bernardis, F., Mondello, F., Ceddia, T., and Agatensi, L. (1987). Evidence for a correlation between proteinase secretion and vulvovaginal candidosis. J. Infect. Dis. 156, 777-783.

Cassone, A., De Bernardis, F., and Santoni, G. (2007). Anticandidal immunity and vaginitis: novel opportunities for immune intervention. Infect. Immun. 75, 4675-4686.

Cassone, A., and Rappuoli, R. (2010). Universal vaccines: shifting to one for many. MBio 1, e00042-10. 
Conti, H. R., Shen, F., Nayyar, N., Stocum, E., Sun, J. N., Lindemann, M. J., Ho, A. W., Hai, J. H., Yu, J. J., Jung, J. W., Filler, S. G., Masso-Welch, P., Edgerton, M., and Gaffen, S. L. (2009). Th17 cells and IL-17 receptor signaling are essential for mucosal host defense against oral candidiasis. J. Exp. Med. 206, 299-311.

Cutler, C. W., and Jotwani, R. (2006). Dendritic cells at the oral mucosal interface. J. Dent. Res. 85, 678-689.

Cutler, J. E. (2005). Defining criteria for anti-mannan antibodies to protect against candidiasis. Curr. Mol. Med. 5, 383-392.

Cutler, J. E., Corti, M., Lambert, P., Ferris, M., and Xin, H. (2011). Horizontal transmission of Candida albicans and evidence of a vaccine response in mice colonized with the fungus. PLoS ONE 6, e22030. doi:10.1371/journal.pone.0022030

Cutler, J. E., Deepe, G. S. Jr., and Klein, B. S. (2007). Advances in combating fungal diseases: vaccines on the threshold. Nat. Rev. Microbiol. 5, 13-28.

De Bernardis, F., Agatensi, L., Ross, I. K., Emerson, G. W., Lorenzini, R., Sullivan, P. A., and Cassone, A. (1990). Evidence for a role for secreted aspartate proteinase of Candida albicans in vulvovaginal candidiasis. $J$. Infect. Dis. 161, 1276-1283.

De Bernardis, F., Amacker, M., Arancia, S., Sandini, S., Gremion, C., Zurbriggen, R., Moser, C., and Cassone, A. (2012). A virosomal vaccine against candidal vaginitis: immunogenicity, efficacy and safety profile in animal models. Vaccine 30, 4490-4498.

De Bernardis, F., Boccanera, M., Adriani, D., Spreghini, E., Santoni, G., and Cassone, A. (1997). Protective role of antimannan and anti-aspartyl proteinase antibodies in an experimental model of Candida albicans vaginitis in rats. Infect. Immun. 65 , 3399-3405.

De Bernardis, F., Santoni, G., Boccanera, M., Lucciarini, R., Arancia, S., Sandini, S., Amantini, C., and Cassone, A. (2010). Protection against rat vaginal candidiasis by adoptive transfer of vaginal B lymphocytes. FEMS Yeast Res. 10, 432-440.

de Bernardis, F., Santoni, G., Boccanera, M., Spreghini, E., Adriani, D., Morelli, L., and Cassone, A. (2000). Local anticandidal immune responses in a rat model of vaginal infection by and protection against Candida albicans. Infect. Immun. 68, 3297-3304.

Diamond, M. E., Sun, L., Ottaviano, A. J., Joseph, M. J., and Munshi, H.
G. (2008). Differential growth factor regulation of $\mathrm{N}$-cadherin expression and motility in normal and malignant oral epithelium. J. Cell. Sci. 121, 2197-2207.

Farah, C. S., Elahi, S., Drysdale, K., Pang, G., Gotjamanos, T., Seymour, G. J., Clancy, R. L., and Ashman, R. B. (2002). Primary role for $\mathrm{CD} 4(+) \mathrm{T}$ lymphocytes in recovery from oropharyngeal candidiasis. Infect. Immun. 70, 724-731.

Fidel, P. L. Jr. (2004). History and new insights into host defense against vaginal candidiasis. Trends Microbiol. 12, 220-227.

Fidel, P. L. Jr. (2006). Candida-host interactions in HIV disease: relationships in oropharyngeal candidiasis. Adv. Dent. Res. 19, 80-84.

Fidel, P. L. Jr. (2007). History and update on host defense against vaginal candidiasis. Am. J. Reprod. Immunol. 57, 2-12.

Fidel, P. L. Jr., and Cutler, J. E. (2011). Prospects for development of a vaccine to prevent and control vaginal candidiasis. Curr. Infect. Dis. Rep. 13, 102-107.

Fidel, P. L. Jr., Luo, W., Steele, C., Chabain, J., Baker, M., and Wormley, F. Jr. (1999). Analysis of vaginal cell populations during experimental vaginal candidiasis. Infect. Immun. 67, 3135-3140.

Han, Y., Riesselman, M. H., and Cutler, J. E. (2000). Protection against candidiasis by an immunoglobulin G3 (IgG3) monoclonal antibody specific for the same mannotriose as an $\operatorname{IgM}$ protective antibody. Infect. Immun. 68, 1649-1654.

Hornef, M. W., and Bogdan, C. (2005). The role of epithelial Toll-like receptor expression in host defense and microbial tolerance. J. Endotoxin Res. $11,124-128$.

Huang, H., Ostroff, G. R., Lee, C. K., Specht, C. A., and Levitz, S. M. (2010). Robust stimulation of humoral and cellular immune responses following vaccination with antigen-loaded betaglucan particles. MBio 1, e00164-10.

Karwa, R., and Wargo, K. A. (2009). Efungumab: a novel agent in the treatment of invasive candidiasis. Ann. Pharmacother. 43, 1818-1823.

Kibbler, C. C., Seaton, S., Barnes, R. A., Gransden, W. R., Holliman, R. E., Johnson, E. M., Perry, J. D., Sullivan, D. J., and Wilson, J. A. (2003). Management and outcome of bloodstream infections due to Candida species in England and Wales. J. Hosp. Infect. 54, 18-24.
Kirkpatrick, C. H. (2001). Chronic mucocutaneous candidiasis. Pediatr. Infect. Dis. J. 20, 197-206.

Klis, F. M., De Koster, C. G., and Brul, S. (2011). A mass spectrometric view of the fungal wall proteome. Future Microbiol. 6, 941-951.

Li, L., and Dongari-Bagtzoglou, A. (2009). Epithelial GM-CSF induction by Candida glabrata. J. Dent. Res. 88, 746-751.

Li, W., Hu, X., Zhang, X., Ge, Y., Zhao, S., Hu, Y., and Ashman, R. B. (2011). Immunisation with the glycolytic enzyme enolase confers effective protection against Candida albicans infection in mice. Vaccine 29 , 5526-5533.

Lim, S. M., Jung, H. S., Kim, M. J., Park, D. W., Kim, W. J., Cheong, H. J., Park, S. C., Lee, K. C., Shin, Y. K., Tan, H. K., Kim, S. L., and Sohn, J. W. (2007). Immunogenicity and safety of Vi capsular polysaccharide typhoid vaccine in healthy persons in Korea. J. Microbiol. Biotechnol. 17 , 611-615.

Lindqvist, M., Nookaew, I., Brinkenberg, I., Samuelson, E., Thorn, K., Nielsen, J., and Harandi, A. M. (2011). Unraveling molecular signatures of immunostimulatory adjuvants in the female genital tract through systems biology. PLoS ONE 6, e20448. doi:10.1371/journal.pone.0020448

Liu, Y., and Filler, S. G. (2011). Candida albicans Als3, a multifunctional adhesin and invasin. Eukaryot. Cell $10,168-173$.

Lopez-Martinez, R. (2010). Candidosis, a new challenge. Clin. Dermatol. 28 , 178-184.

Luo, G., Ibrahim, A. S., French, S. W., Edwards, J. E. Jr., and Fu, Y. (2011). Active and passive immunization with $\mathrm{rHyr} 1 \mathrm{p}-\mathrm{N}$ protects mice against hematogenously disseminated candidiasis. PLOS ONE 6, e25909. doi:10.1371/journal.pone.0025909

Matthews, R. C., Rigg, G., Hodgetts, S., Carter, T., Chapman, C., Gregory, C., Illidge, C., and Burnie, J. (2003). Preclinical assessment of the efficacy of mycograb, a human recombinant antibody against fungal HSP90. Antimicrob. Agents Chemother. 47, 2208-2216.

Moyes, D. L., and Naglik, J. R. (2011). Mucosal immunity and Candida albicans infection. Clin. Dev. Immunol. 2011, 346307.

Moyes, D. L., Runglall, M., Murciano, C., Shen, C., Nayar, D., Thavaraj, S., Kohli, A., Islam, A., MoraMontes, H., Challacombe, S. J. and Naglik, J. R. (2010). A biphasic innate immune MAPK response discriminates between the yeast and hyphal forms of Candida albicans in epithelial cells. Cell Host Microbe 8, 225-235.

Naglik, J. R., Challacombe, S. J., and Hube, B. (2003). Candida albicans secreted aspartyl proteinases in virulence and pathogenesis. Microbiol. Mol. Biol. Rev. 67, 400-428.

Naglik, J. R., and Moyes, D. (2011). Epithelial cell innate response to Candida albicans. Adv. Dent. Res. 23, 50-55.

Netea, M. G., Brown, G. D., Kullberg, B. J., and Gow, N. A. (2008). An integrated model of the recognition of Candida albicans by the innate immune system. Nat. Rev. Microbiol. 6, 67-78.

Netea, M. G., Gow, N. A., Munro, C. A., Bates, S., Collins, C., Ferwerda, G., Hobson, R. P., Bertram, G., Hughes, H. B., Jansen, T., Jacobs, L., Buurman, E. T., Gijzen, K., Williams, D. L., Torensma, R., McKinnon, A., MacCallum, D. M., Odds, F. C., Van Der Meer, J. W., Brown, A. J., and Kullberg, B. J. (2006). Immune sensing of Candida albicans requires cooperative recognition of mannans and glucans by lectin and Toll-like receptors. J. Clin. Invest. 116, 1642-1650.

Perruccio, K., Bozza, S., Montagnoli, C., Bellocchio, S., Aversa, F., Martelli, M., Bistoni, F., Velardi, A., and Romani, L. (2004). Prospects for dendritic cell vaccination against fungal infections in hematopoietic transplantation. Blood Cells Mol. Dis. 33, 248-255.

Pfaller, M. A., Jones, R. N., Messer, S. A., Edmond, M. B., and Wenzel, R. P. (1998a). National surveillance of nosocomial blood stream infection due to Candida albicans: frequency of occurrence and antifungal susceptibility in the SCOPE program. Diagn. Microbiol. Infect. Dis. $31,327-332$.

Pfaller, M. A., Jones, R. N., Messer, S. A., Edmond, M. B., and Wenzel, R. P. (1998b). National surveillance of nosocomial blood stream infection due to species of Candida other than Candida albicans: frequency of occurrence and antifungal susceptibility in the SCOPE program. SCOPE participant group. Surveillance and control of pathogens of epidemiologic. Diagn. Microbiol. Infect. Dis. 30, 121-129.

Pietrella, D., Mazzolla, R., Lupo, P., Pitzurra, L., Gomez, M. J., Cherniak, R., and Vecchiarelli, A. (2002). Mannoprotein from Cryptococcus neoformans promotes T-helper type 1 anticandidal responses in mice. Infect. Immun. 70, 6621-6627. 
Pietrella, D., Rachini, A., Torosantucci, A., Chiani, P., Brown, A. J., Bistoni, F., Costantino, P., Mosci, P., D'enfert, C., Rappuoli, R., Cassone, A., and Vecchiarelli, A. (2010). A betaglucan-conjugate vaccine and antibeta-glucan antibodies are effective against murine vaginal candidiasis as assessed by a novel in vivo imaging technique. Vaccine 28, 1717-1725.

Pirofski, L. A., and Casadevall, A. (2009). Rethinking T cell immunity in oropharyngeal candidiasis. J. Exp. Med. 206, 269-273.

Pirofski, L. A., and Casadevall, A. (2012). $\mathrm{Q}$ and $\mathrm{A}$ : what is a pathogen? A question that begs the point. BMC Biol. 10, 6. doi:10.1186/1741-7007-10-6

Polonelli, L., Ciociola, T., Magliani, W., Zanello, P. P., D'adda, T., Galati, S., De Bernardis, F., Arancia, S., Gabrielli, E., Pericolini, E., Vecchiarelli, A., Arruda, D. C., Pinto, M. R., Travassos, L. R., Pertinhez, T. A., Spisni, A., and Conti, S. (2012). Peptides of the constant region of antibodies display fungicidal activity. PLoS ONE 7, e34105. doi:10.1371/journal.pone.0034105

Polonelli, L., De Bernardis, F., Conti, S., Boccanera, M., Gerloni, M., Morace, G., Magliani, W., Chezzi, C., and Cassone, A. (1994). Idiotypic intravaginal vaccination to protect against candidal vaginitis by secretory, yeast killer toxin-like anti-idiotypic antibodies. J. Immunol. 152, 3175-3182.

Rahman, D., Mistry, M., Thavaraj, S., Challacombe, S. J., and Naglik, J. R. (2007). Murine model of concurrent oral and vaginal Candida albicans colonization to study epithelial host-pathogen interactions. Microbes Infect. 9, 615-622.

Raska, M., Belakova, J., Horynova, M., Krupka, M., Novotny, J., Sebestova, M., and Weigl, E. (2008). Systemic and mucosal immunization with Candida albicans hsp90 elicits hsp90-specific humoral response in vaginal mucosa which is further enhanced during experimental vaginal candidiasis. Med. Mycol. 46, 411-420.

Remichkova, M., Danova, S., Tucureanu, C., Lerescu, L., Salageanu, A., and Dimitrova, P. (2009). Effect of Candida albicans dsDNA in gastrointestinal Candida infection. Mycopathologia 167,333-340.

Rhee, S. H., Im, E., Riegler, M., Kokkotou, E., O'brien, M., and Pothoulakis,
C. (2005). Pathophysiological role of Toll-like receptor 5 engagement by bacterial flagellin in colonic inflammation. Proc. Natl. Acad. Sci. U.S.A. 102, 13610-13615.

Roeder, A., Kirschning, C. J., Rupec, R. A., Schaller, M., and Korting, H. C. (2004a). Toll-like receptors and innate antifungal responses. Trends Microbiol. 12, 44-49.

Roeder, A., Kirschning, C. J., Rupec, R. A., Schaller, M., Weindl, G., and Korting, H. C. (2004b). Toll-like receptors as key mediators in innate antifungal immunity. Med. Mycol. $42,485-498$.

Roy, R. M., and Klein, B. S. (2012), Dendritic cells in antifungal immunity and vaccine design. Cell Host Microbe 11, 436-446.

Sandini, S., La Valle, R., Deaglio, S., Malavasi, F., Cassone, A., and De Bernardis, F. (2011). A highly immunogenic recombinant and truncated protein of the secreted aspartic proteases family (rSap2t) of Candida albicans as a mucosal anticandidal vaccine. FEMS Immunol. Med. Microbiol. 62, 215-224.

Schaller, M., Boeld, U., Oberbauer, S., Hamm, G., Hube, B., and Korting, H. C. (2004). Polymorphonuclear leukocytes (PMNs) induce protective Th1-type cytokine epithelial responses in an in vitro model of oral candidosis. Microbiology 150, 2807-2813.

Shaykhiev, R., Behr, J., and Bals, R. (2008). Microbial patterns signaling via Toll-like receptors 2 and 5 contribute to epithelial repair, growth and survival. PLOS ONE 3, e1393. doi:10.1371/journal.pone. 0001393

Sobel, J. D. (2007). Vulvovaginal candidosis. Lancet 369, 1961-1971.

Spellberg, B., Ibrahim, A. S., Yeaman, M. R., Lin, L., Fu, Y., Avanesian, V., Bayer, A. S., Filler, S. G., Lipke, P., Otoo, H., and Edwards, J. E. Jr. (2008). The antifungal vaccine derived from the recombinant $\mathrm{N}$ terminus of Als3p protects mice against the bacterium Staphylococcus aureus. Infect. Immun. 76, 4574-4580.

Spellberg, B. J., Ibrahim, A. S., Avanesian, V., Fu, Y., Myers, C., Phan, Q. T., Filler, S. G., Yeaman, M. R., and Edwards, J. E. Jr. (2006). Efficacy of the anti-Candida rAls3p-N or rAls1 p-N vaccines against disseminated and mucosal candidiasis. $J$. Infect. Dis. 194, 256-260.

Stuehler, C., Khanna, N., Bozza, S., Zelante, T., Moretti, S., Kruhm, M. Lurati, S., Conrad, B., Worschech, E., Stevanovic, S., Krappmann, S. Einsele, H., Latge, J. P., Loeffler, J., Romani, L., and Topp, M. S. (2011). Cross-protective TH1 immunity against Aspergillus fumigatus and Candida albicans. Blood 117, 5881-5891.

Torosantucci, A., Bromuro, C., Chiani, P., De Bernardis, F., Berti, F., Galli, C., Norelli, F., Bellucci, C., Polonelli, L., Costantino, P., Rappuoli, R. and Cassone, A. (2005). A novel glyco-conjugate vaccine against fungal pathogens. J. Exp. Med. 202, 597-606.

Torosantucci, A., Chiani, P., Bromuro, C., De Bernardis, F., Palma, A. S. Liu, Y., Mignogna, G., Maras, B. Colone, M., Stringaro, A., Zamboni, S., Feizi, T., and Cassone, A. (2009). Protection by anti-betaglucan antibodies is associated with restricted beta- 1,3 glucan binding specificity and inhibition of fungal growth and adherence. PLOS ONE 4, e5392. doi:10.1371/journal.pone. 0005392

Trinchieri, G. (2003). Interleukin-12 and the regulation of innate resistance and adaptive immunity. Nat. Rev. Immunol. 3, 133-146.

Weindl, G., Naglik, J. R., Kaesler, S. Biedermann, T., Hube, B., Korting, H. C., and Schaller, M. (2007). Human epithelial cells establish direct antifungal defense through TLR4-mediated signaling. J. Clin. Invest. 117, 3664-3672.

Wuthrich, M., Gern, B., Hung, C. Y., Ersland, K., Rocco, N., Pick-Jacobs, J. Galles, K., Filutowicz, H., Warner, T., Evans, M., Cole, G., and Klein, B. (2011). Vaccine-induced protection against 3 systemic mycoses endemic to North America requires Th17 cells in mice. J. Clin. Invest. 121, 554-568.

Xin, H., Cartmell, J., Bailey, J. J. Dziadek, S., Bundle, D. R., and Cutler, J. E. (2012). Selfadjuvanting glycopeptide conjugate vaccine against disseminated candidiasis. PLOS ONE 7, e35106 doi:10.1371/journal.pone.0035106

Xin, H., and Cutler, J. E. (2011). Vaccine and monoclonal antibody that enhance mouse resistance to candidiasis. Clin. Vaccine Immunol. 18 , 1656-1667.

Xin, H., Dziadek, S., Bundle, D. R., and Cutler, J. E. (2008). Synthetic glycopeptide vaccines combining beta-mannan and peptide epitopes induce protection against candidiasis. Proc. Natl. Acad. Sci. U.S.A. 105, 13526-13531.

Yang, Q., Wang, L., Lu, D. N., Gao, R. J., Song, J. N., Hua, P. Y., and Yuan, D. W. (2005). Prophylactic vaccination with phage-displayed epitope of C. albicans elicits protective immune responses against systemic candidiasis in C57BL/6 mice. Vaccine 23 4088-4096.

Yano, J., Lilly, E., Barousse, M., and Fidel, P. L. Jr. (2010). Epithelial cellderived S100 calcium-binding proteins as key mediators in the hallmark acute neutrophil response during Candida vaginitis. Infect. Immun. 78, 5126-5137.

Zakikhany, K., Naglik, J. R., SchmidtWesthausen, A., Holland, G., Schaller, M., and Hube, B. (2007). In vivo transcript profiling of Candida albicans identifies a gene essential for interepithelial dissemination. Cell. Microbiol. 9, 2938-2954.

Conflict of Interest Statement: The authors declare that the research was conducted in the absence of any commercial or financial relationships that could be construed as a potential conflict of interest.

Received: 02 July 2012; accepted: 24 July 2012; published online: 13 August 2012. Citation: Vecchiarelli A, Pericolini E, Gabrielli E and Pietrella D (2012) New approaches in the development of a vaccine for mucosal candidiasis: progress and challenges. Front. Microbio. 3:294. doi: 10.3389/fmicb.2012.00294

This article was submitted to Frontiers in Fungi and Their Interactions, a specialty of Frontiers in Microbiology. Copyright () 2012 Vecchiarelli, Pericolini, Gabrielli and Pietrella. This is an open-access article distributed under the terms of the Creative Commons Attribution License, which permits use, distribution and reproduction in other forums, provided the original authors and source are credited and subject to any copyright notices concerning any third-party graphics etc. 